This item was submitted to Loughborough's Research Repository by the author.

Items in Figshare are protected by copyright, with all rights reserved, unless otherwise indicated.

\title{
Slips, trips and falls in crowds
}

\section{PLEASE CITE THE PUBLISHED VERSION}

https://doi.org/10.1007/978-3-319-96089-0_82

\section{PUBLISHER}

(C) Springer

\section{VERSION}

AM (Accepted Manuscript)

\section{PUBLISHER STATEMENT}

This is a pre-copyedited version of a contribution published in Bagnara, S. ... et al. (eds.) 20th International Ergonomics Association (IEA2018): Volume IX: Aging, Gender and Work, Anthropometry, Ergonomics for Children and Educational Environments published by Springer. The definitive authenticated version is available online via https://www.springer.com/us/book/9783319960647

\section{LICENCE}

CC BY-NC-ND 4.0

\section{REPOSITORY RECORD}

Haslam, Roger, and Victoria Filingeri. 2019. "Slips, Trips and Falls in Crowds". figshare. https://hdl.handle.net/2134/34816. 


\title{
Slips, trips and falls in crowds
}

\author{
Roger Haslam ${ }^{1[0000-0001-7842-9171]}$ and Victoria Filingeri ${ }^{\text {[0000-0002-7140-2790] }}$ \\ ${ }^{1}$ Loughborough University, UK \\ r.a.haslam@lboro.ac.uk \\ ${ }^{2}$ University of Derby, UK \\ v.filingeri@derby.ac.uk
}

\begin{abstract}
Crowd situations are commonplace and involve circumstances known to lead to slips, trips and falls (STF). Data from focus groups with crowd participants (5 groups, $\mathrm{n}=35$ individuals); observations of crowd situations $(n=55)$; and interviews with crowd organisers $(n=41)$ were analysed to examine understanding of and responses to the risk of STF in crowds. Although safety was a high priority for both crowd participants and organisers, explicit consideration of STF as a safety concern was low among both groups. Crowd observations found STF risks mitigated on some occasions and present on others, without any discernible pattern for the variation. A risk management framework for STF risk in crowds is proposed. It is concluded that improved understanding is needed of the nature and pattern of STF occurrence in crowds and the efficacy of measures for prevention.
\end{abstract}

Keywords: Crowd ergonomics, crowd safety, fall prevention.

\section{Introduction}

Slips, trips and falls (STF) are a leading cause of unintentional injury for both occupational and leisure activities [1]. Falls involve a loss of balance due to some reason, which results in a person falling to the ground or other lower level. Aspects of the environment involved in falls are the foot-floor interface and the presence of trip hazards. The frictional characteristics of footwear and flooring materials affect the likelihood of slipping, with these influenced by their condition and maintenance and also the presence of contaminants (e.g. water, ice, litter). Obstacles in the walkway may lead to tripping if they go unnoticed by the pedestrian. Because the clearance between feet and the floor is small during normal gait, deviations in the walking surface of as little as $10 \mathrm{~mm}$ may be sufficient to cause a trip. Other perturbations of balance may result from contact with objects or people (e.g. bumping into or being pushed by something or someone). Although the multi-factorial causality of STF is reasonably well understood, efforts to reduce the incidence of injury, however, have had mixed success [2].

Gatherings of large numbers of people, crowds, are a ubiquitous part of our human experience. Crowds are encountered in circumstances such as using public transport, visiting retail environments or participating in entertainment events (e.g. sport 
matches, music festivals, amusement parks, museums etc.). Crowds occur in wide ranging environments e.g. streets, fields, sports stadia, concert halls, shopping malls, airports, railway stations etc. In some situations, the management and infrastructure are permanent; in others the conditions and oversight are transitory. The nature of a crowd can vary from good humoured, sedate and purposeful to angry, excited and in disarray.

Crowding can exacerbate risk factors for STF, with the proximity of large numbers of individuals leading to deterioration of the walking surface or obstructed vision, for example. Crowd movement can result in jostling or pushing. STF in crowd situations can have serious consequences, for both the faller and others involved in the gathering. An individual STF in a moving crowd can result in obstruction to the crowd flow and further multiple fall or crush injuries. Such crowd 'disasters', receive considerable attention from news media, with reporting of deaths and injuries at events such as pilgrimages and festivals regular occurrences. Data on the incidence, injuries and causes of STF in crowds, however, are not collected in a systematic manner and with significant underreporting. Data that are available suggest that slips are more frequent than trips and that risk increases with older age and when carrying items or in the presence of luggage. Consumption of alcohol is also implicated [3].

Filingeri et al. [4,5] reported the findings of interview and observations studies of multiple crowd situations, which examined the factors affecting crowd participant experience. This paper presents further analysis of the data from these studies, focusing on risk and management of STF in crowd situations.

\section{Method}

The research employed a combination of focus groups, observations and interviews. Five focus groups (35 individuals, age range: 21-71 years) were conducted to collect in-depth accounts of the features of crowd situations important to crowd participants. Observations were then undertaken of 55 crowd situations, to identify aspects that contribute to positive and negative experience of crowds. The researcher observed crowds as a participant observer, using a standardised checklist as a prompt for recording audio notes, video and photographs, enabling crowd situations to be observed consistently and systematically. The crowds observed encompassed a wide variety of type, size, purpose and participant culture. Observations covered a range of seasons and weather conditions. Semi-structured interviews were conducted separately $(n=41)$ with organisers responsible for different aspects of the design, planning, management and operation of events and other crowd situations. The objective was to understand organisers' priorities, along with the consideration given to the experience of crowd participants.

\section{$3 \quad$ Results}

Safety was one of the most frequently mentioned topics in the focus groups. This was regarded as an important concern affecting crowd satisfaction across crowd partici- 
pant demographics, with STF hazards, trampling risks and violence being discussed. In the words of one focus group member:

"But you just... you would just feel like you were being pushed along on a wave wouldn't you...? And if anything happened... if somebody stumbled over or something you'd... phh... not a hope have you...?"

(Healthy Adults focus group, female aged 47 years).

The crowd observations identified many instances where STF hazards had been identified and risks controlled (Table 1). There were also many examples seen where STF risk was present (Table 2). Figure 1 illustrates the litter problems that can occur with large scale events and the ensuing risk of slipping or tripping on the debris.

Table 1. Examples from observations of mitigated STF risks

\begin{tabular}{|c|c|}
\hline Hazard & Observation notes \\
\hline Wet floor surface & $\begin{array}{l}\text { Retail events } 1 \text { - Christmas Market (city centre): Non-slip } \\
\text { floor boarding in the cathedral square area. Important when } \\
\text { the rain began to pour. }\end{array}$ \\
\hline Muddy floor surface & $\begin{array}{l}\text { Music events } 6 \text { - Outdoor Music Festival: Straw and hay } \\
\text { placed down over very muddy patches of ground, to prevent } \\
\text { accidents. }\end{array}$ \\
\hline Severe weather conditions & $\begin{array}{l}\text { Retail events } 1 \text { - Christmas Market (city centre): Event can- } \\
\text { celled for the first time in many years, due to heavy snow } \\
\text { and ice and risk of STF. }\end{array}$ \\
\hline Temporary cables & $\begin{array}{l}\text { Conferences and exhibitions } 26 \text { - University careers fair: } \\
\text { Cables were stuck to the ground with thick black tape to } \\
\text { reduce the risk. }\end{array}$ \\
\hline Low level steps & $\begin{array}{l}\text { Participatory events } 36 \text { - Fairground (town centre): Pave- } \\
\text { ment slopes implemented to prevent tripping on curb. }\end{array}$ \\
\hline Stair safety & $\begin{array}{l}\text { Theatre event } 42 \text { - Musical show (London): Handrails along } \\
\text { stairs in-between the theatre seated tiered sections. }\end{array}$ \\
\hline Poor lighting & $\begin{array}{l}\text { Music events } 8 \text { - Classical Concert (Vienna): Clear exit } \\
\text { routes were lit up within the concert area. }\end{array}$ \\
\hline
\end{tabular}

Interviews with organisers of crowd situations found that health and safety was a key consideration, receiving greater attention than other aspects such as crowd participants' goal achievement, comfort and satisfaction. The protection of crowd users, prevention of accidents, protecting venue reputation and legal obligations were discussed as reasons for devoting time and resources to health and safety during crowd events. STF related aspects, however, were only mentioned explicitly in 3 of the 41 organiser interviews. One interviewee highlighted the serious consequences that can ensue from falls in a crowd: 
And then the doormen start coming back in... because it can be that dangerous. Because crowds surging... moving and so we're trained in specific ways, to see that people can get them out. And again, the worst thing is somebody falling over in a crowd..."

(Security officer, music events, interviewee 10)

An event planner involved in sporting events and a police interviewee discussed the problems arising from poor weather. The event planner, for example, stated:

"That's the trickiest thing in the bad weather. I mean, the main thing is having good trained marshals in place ... so if there are slippery banks or bottlenecks, then you try to clear them."

(Event planner, outdoor spectator events, interviewee 16)

In both these extracts, the interviewees pointed to the importance of having trained personnel to identify and respond to problems.

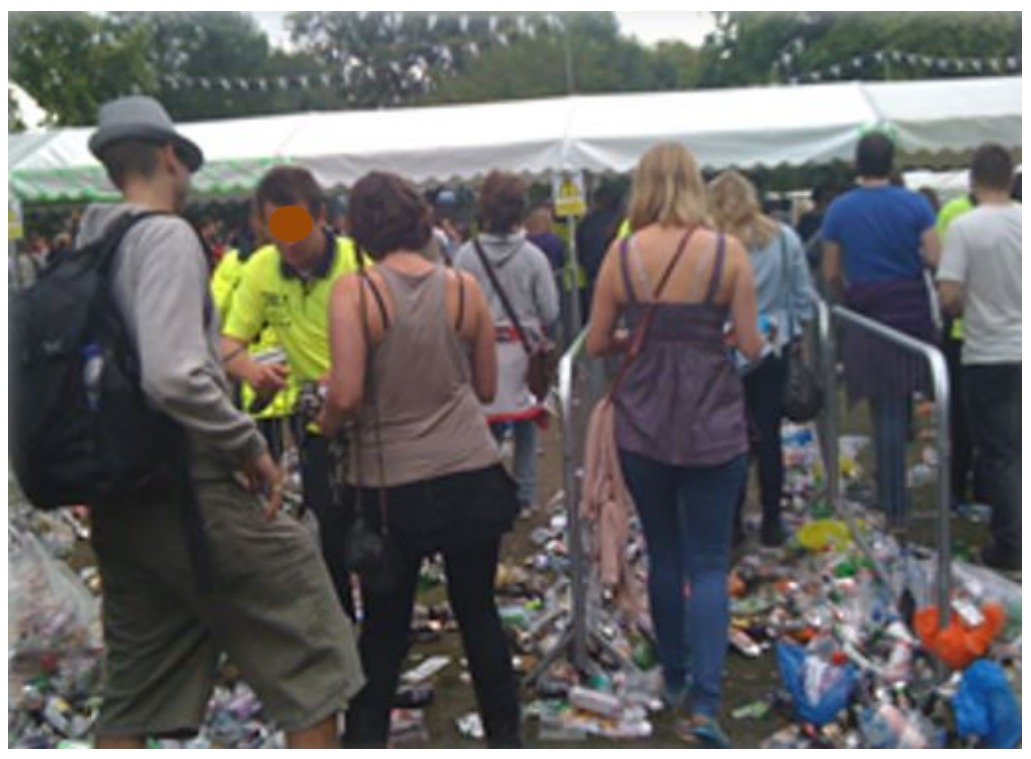

Fig. 1. Litter posing risk of STF (Music events 4 - Victoria Park, London) 
Table 2. Examples from observations where STF risk was present

\begin{tabular}{|c|c|}
\hline Hazard & Observation notes \\
\hline Wet flooring & $\begin{array}{l}\text { Music events } 5 \text { - Pub (city centre): Getting a number of } \\
\text { drinks from the bar back to the other people in your group is } \\
\text { difficult, causing spillages. Wet areas on the floor were } \\
\text { dangerous when walking (especially when carrying drinks). }\end{array}$ \\
\hline Wet flooring & $\begin{array}{l}\text { Retail } 47 \text { - Shopping centre (city centre): Water from outside } \\
\text { brought inside on shoes, causing a slip hazard. }\end{array}$ \\
\hline Litter & $\begin{array}{l}\text { Music events } 2 \text { - Arena (city centre): Rubbish thrown on the } \\
\text { floor - plastic cups/bottles. Did not see bins, or areas to } \\
\text { dispose rubbish. No staff seen to be collecting litter. On } \\
\text { exiting event - plastic cups lined the floor. All creating STF } \\
\text { hazards. }\end{array}$ \\
\hline Litter & $\begin{array}{l}\text { Participatory events } 35 \text { - Carnival (Brazil): Litter every- } \\
\text { where, food and litter lined the streets. No personnel to } \\
\text { collect the litter throughout the event. STF hazards. }\end{array}$ \\
\hline Inadequate lighting & $\begin{array}{l}\text { Theatre event } 43 \text { - Cinema (town centre): Dark as you enter } \\
\text { and exit the cinema screen, the room is dark, and although } \\
\text { the seat numbers are lit up, it provides a safety hazard. }\end{array}$ \\
\hline $\begin{array}{l}\text { Restricted space for entry/ } \\
\text { egress }\end{array}$ & $\begin{array}{l}\text { Sporting events } 14 \text { - Rugby match (rugby stadium): Stand- } \\
\text { ing on tiered seating section, having to climb across people } \\
\text { to get out. Steep and restricted space. Some people do not } \\
\text { stand to allow others to pass, and instead try to move their } \\
\text { feet to one side allowing limited space. }\end{array}$ \\
\hline Escalator fall & $\begin{array}{l}\text { Transport hub } 31-\text { Underground (London): Two older } \\
\text { women fell backwards at the base of the escalator causing a } \\
\text { blockage. No one pressed the emergency stop button and so } \\
\text { oncoming pedestrians had to try and jump over the women, } \\
\text { as people at the bottom attempted to help them to stand. The } \\
\text { emergency stop buttons were placed too far away from the } \\
\text { point the fall occurred. The emergency stop buttons were } \\
\text { also not close enough to other participants who were on the } \\
\text { escalators who tried to help. }\end{array}$ \\
\hline Escalator fall & $\begin{array}{l}\text { Transport hub } 34 \text { - Metro (Vienna): An older man (estimat- } \\
\text { ed over } 70 \text { years) fell backwards on the escalator. I pressed } \\
\text { the emergency button from the bottom of the escalator and } \\
\text { other passengers helped to get the man to the top of the } \\
\text { escalator until assistance came. }\end{array}$ \\
\hline Encumbrances & $\begin{array}{l}\text { Theatre event } 44 \text { - Arena (city centre): Little space available } \\
\text { to store belonging like bags and coats. Cloakroom available } \\
\text { but put off by long queues. }\end{array}$ \\
\hline
\end{tabular}




\section{Discussion}

Our investigations found safety to be an important concern for both crowd organisers and crowd participants. Although STF are a prominent cause of injury, the relatively few references in the focus group and interview discussions to STF was not in line with the safety implications that these incidents pose. The STF mitigations seen in the observation study, however, indicated that STF risks on these occasions had been considered and addressed, to some extent at least.

Where STF risks were apparent in the crowd situations observed, these arose from shortcomings with the built environment and permanent infrastructure as well as more variable environmental and behavioural components and the organiser responses to these. Although it might be expected that STF safety of locations designed for hosting crowds would be to a high standard, previous studies have highlighted deficiencies with the design of walkways, steps, handrails etc. in major event venues. In a premier league football stadium, for example, problems were identified with the physical design and layout of seating areas and entrance and egress routes, especially the narrow clearway between seat rows, irregular and excessive step dimensions and unmarked step edges [6,7]. Regarding escalators, the risk of falls posed by these is well known, with public education campaigns visible as a response [8].

The role of crowd organisers is pivotal in controlling STF risks, both to design out hazards but also in managing the complex individual and collective behaviour of people in crowds. This is especially the case for crowds occurring in temporary surroundings (e.g. street or field festivals). In a wider examination of the activities of crowd organisers, Filingeri et al [5] found that organisers tended to rely on experience and judgement in approaching their planning and decisions, without accessing training or the guidance materials available. The organisers of infrequent or small-scale events can have the greatest knowledge and experience gap. It was suggested that the non-use of guidance is in part due to problems with the guidance currently available, both its content and its form. With regard to STF, key guidance available concerning safety at sporting and music events gives only cursory attention to how STF hazards can be addressed $[9,10]$.

Along with the lack of data and analysis on the extent and nature of STF in crowds, there is also a scarcity of research evidence on the effectiveness of different forms of control and intervention to prevent STF injury. In the absence of this, an adapted STF risk control framework for crowds is proposed (Table 3), based on the approach we have presented previously for generic and occupational circumstances [1,2].

\section{Conclusions}

Crowd situations, combining a high density of people, high volumes of pedestrian movement, sometimes in unfamiliar, unpredictable and less than ideal locations, provide a combination of circumstances that can lead to STF. STF in crowds, however, are surprisingly under-researched. Better understanding is needed of the nature and pattern of STF occurrence in crowds and the efficacy of measures for prevention. 
Table 3. Prevention measures for STF in crowds, adapted from [1,2]

Primary Prevention - eliminate STF hazards at source

- Provide slip resistant flooring

- Design facilities (e.g. catering, washrooms) to avoid presence of fall risks (systems approach, with attention to environment, equipment, layout, tasks and people)

- Cover outside walkways to keep off rain, snow, ice, leaves

- Design walkways to exclude trip hazards

- Plan pedestrian routes to allow sufficient space between individuals

- Separate pedestrians from moving machinery and vehicles

- Provide sufficient, convenient space for onsite storage

- Avoid presence of low steps

- Install steps and stairs of appropriate dimensions

- Provide step edges with good contrast

- Install handrails

- Avoid visual distraction in step/stair locations

- Avoid need for walking/standing on surfaces that move unpredictably

- Install grab rails and hand holds

- Install adequate lighting

- Design and select environment features to facilitate cleaning and maintenance

- Design and select environment features for durability and resistance to damage

Risk Reduction - reduce risk of hazards that continue to be present

- Educate and raise awareness of fall risks and fall consequences

- Perform fall risk assessments and implement controls

- Organise sustainable housekeeping procedures for inspection, cleaning and maintenance

- Manage fall risks introduced during installation, cleaning and maintenance

- Provide warning signs for slip hazards

- Mark trip hazards

- Provide durable marking of step edges

- Fit additional handrails

- Fit additional grab rails

- Fit barriers for edge protection

- Encourage use of lighting

- Discourage carrying of awkward, heavy items

- Avoid creating circumstances that encourage rushing

- Implement risk management protocols for inclement weather

- Implement risk management protocols for those at increased risk of falling

- Provide assistive mobility aids for those in need

Maximise Capability - individual responses

- Encourage use of suitable footwear

- Encourage use of suitable clothing

- Facilitate moderation with alcohol consumption 


\section{References}

1. Haslam, R., Stubbs D.: Understanding and Preventing Falls. CRC Press, Boca Raton (2006).

2. Chang, W-R., Leclercq, S., Lockhart, T.E., Haslam, R.: State of science: Occupational slips, trips and falls on the same level. Ergonomics, 59, 861-883 (2016).

3. Kendrick, V.L.: The user experience of crowds. PhD Thesis, Loughborough University (2013). https://dspace.lboro.ac.uk/2134/13888.

4. Filingeri, V., Eason, K., Waterson, P., Haslam, R.: Factors influencing experience in crowds - the participant perspective. Applied Ergonomics, 59, 431-441 (2017).

5. Filingeri, V., Eason, K., Waterson, P., Haslam, R.: Factors influencing experience in crowds - the organiser perspective. Applied Ergonomics, 68, 18-27 (2018).

6. Au, S.Y.Z., Gilroy, J., Livingston, A.D., Haslam, R.A.: Assessing spectator safety in seated areas at a football stadium. In: McCabe, P.T. (ed.), Contemporary Ergonomics 2004, pp. 23-27. CRC Press, Boca Raton (2004).

7. Haslam, R.A., Au, S.Y.Z., Gilroy, J., Livingston, A.D.: 2004, Slip, trip, fall related hazards at a football stadium. In: McCabe, P.T. (ed.), Contemporary Ergonomics 2004, pp. 18-22. CRC Press, Boca Raton (2004).

8. Waterson, P.E., Kendrick, V.L., Ryan, B., Jun, G.T., Haslam, R.A.: Probing deeper into the risks of slips, trips and falls for an ageing rail passenger population. IET Intelligent Transport Systems, 10, 25-31 (2016).

9. Health and Safety Executive (HSE): Managing crowds safely: a guide for organisers at events and venues (2010). Available at:.http://www.hse.gov.uk/pubns/priced/hsg154.pdf, last accessed 2017/2/5.

10. Events Industry Forum (EIF): The purple guide to health, safety and welfare at music and other events (2016). Available at:.http://www.thepurpleguide.co.uk/, last accessed 2017/2/5. 